32.P8

\title{
An Immortalized Rat Schwann Cell Line (SEAD): A Source of Neurotrophic Factors and Its Implications for Neural Grafting
}

\author{
Eileen L. Imperato, Mary F.D. Notter, and John T. Hansen \\ Department of Neurobiology and Anatomy, University of Rochester \\ School of Medicine and Dentistry, Rochester, NY 14642, USA
}

The clinical implications of peripheral and central nervous system (PNS and CNS) regeneration are extensive. Although the precise mechanisms involved in regeneration remain unknown, studies of PNS regeneration offer many insights. For example, Schwann cells may play a key role in peripheral nerve regeneration by providing a trophic environment for regenerating or sprouting neurites. Additionally, previous transplant studies have demonstrated an enhanced survival of implanted cells when cografted with peripheral nerve segments. The principal cell type in these nerve segments thought to be responsible for the increased graft survival is the Schwann cell. Schwann cells are a known source of neuronotrophic factors including nerve growth factor (NGF) and insulin-like growth factor-1 (IGF-1) in vivo. The expression of NGF can be assessed by immunoreactive staining for NGF-receptor in cultured Schwann cells. In the present study, we established and characterized a genetically engineered immortalized rat clonal Schwann cell line (SEAD).

SEAD cells were developed by gene transfer of the $12 \mathrm{~S}$ E1A gene (12S early region $1 \mathrm{~A}$ ) using a retroviral vector. $\Psi 2$ cells were transfected with the retrovirus containing the $12 \mathrm{~S}$ E1A sequence from an adenovirus and the neomycin resistance gene /1/. Mitotically stimulated rat sciatic nerve primary Schwann cell cultures were infected by co-culture with $\Psi 2$ cells for one week. Infected Schwann cells were selected by G418 resistance after 21 days. The resulting cultures were closed by limiting dilution four successive times and showed an 8-fold increase in mitotic index over a three day period compared to primary cultures of Schwann cells harvested from neonatal rat sciatic nerve. SEAD cells maintained immunoreactivity to the typical
Schwann cell marker S-100. Additionally, SEAD cells were positive for the neuronotrophic factors IGF-1 and NGF-receptor as determined immunocytochemically $/ 3 /$. In comparison, primary cultures of Schwann cells were found also to express IGF-1-like immunoreactivity. This is the first example of in vitro staining of IGF-1 in both types of Schwann cells.

$12 \mathrm{~S}$ E1A was reported by several groups to produce non-tumorigenic cell lines from a variety of primary cell cultures $/ 1,2 /$. Similarly, SEAD cells showed no growth in soft agar assays in the presence of serum, confirming their nontumorigenicity. Likewise, co-cultures of SEAD cells and NIH/3T3 cells failed to demonstrate any infection of this fibroblast cell line by virus from the SEAD cells. However, subsequent ultrastructural analysis demonstrated occasional viral particle budding from SEAD cells. While the soft agar assay is considered very reliable, these ultrastructural observations were disturbing. Subsequent injections of SEAD cells into nude mice demonstrated hyperplastic subcutaneous growth of the SEAD cells but no metastases to surrounding tissues, lymph nodes or major organs. While we are continuing to examine this paradox, it appears that SEAD cells may represent an immortalized nontumorigenic Schwann cell line that has the potential for further investigation into Schwann gene cell regulation and/or in vivo transplant studies where the trophic aspects of the cells may enhance neuronal sprouting or graft cell survival. The advantages of a non-tumorigenic immortalized Schwann cell line are obvious, especially for grafting studies where large numbers of Schwann cells may be desirable for co-grafting with trophic factor dependent cells such as adrenal chromaffin tissue. 
Supported by NIH grant NS 25778 and EY 06947.

\section{REFERENCES}

1. Cone RD, Grodzicker T, Jaramillo M. A retrovirus expressing the $12 \mathrm{~S}$ adenovirus E1A gene product can immortalize epithelial cells from a broad range of rat tissues. Mol Cellul Biol 1988; 8(3): 1036-1044.

2. He X, Frank DP, Tabak LA. Establishment and characterization of $12 \mathrm{~S}$ adenoviral E1A immortalized rat submandibular gland epithelial cells. Biochem Biophys Res Comm 1990; 170(1): 336-343.

3. Imperato EL, Notter MFD, Hansen JT. Normal and SEAD rat Schwann cells are immunoreactive for insulin-like growth factor-1 and nerve growth factor receptor. Soc Neurosci Abst 1991; 17(2): 1502. 

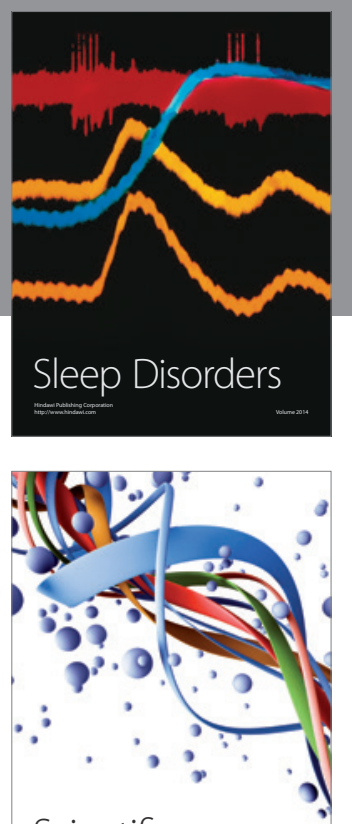

Scientifica
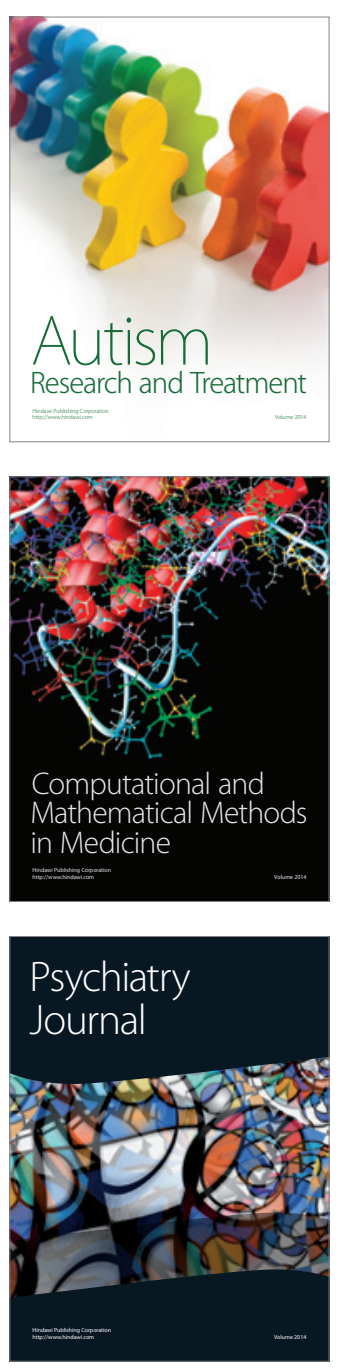
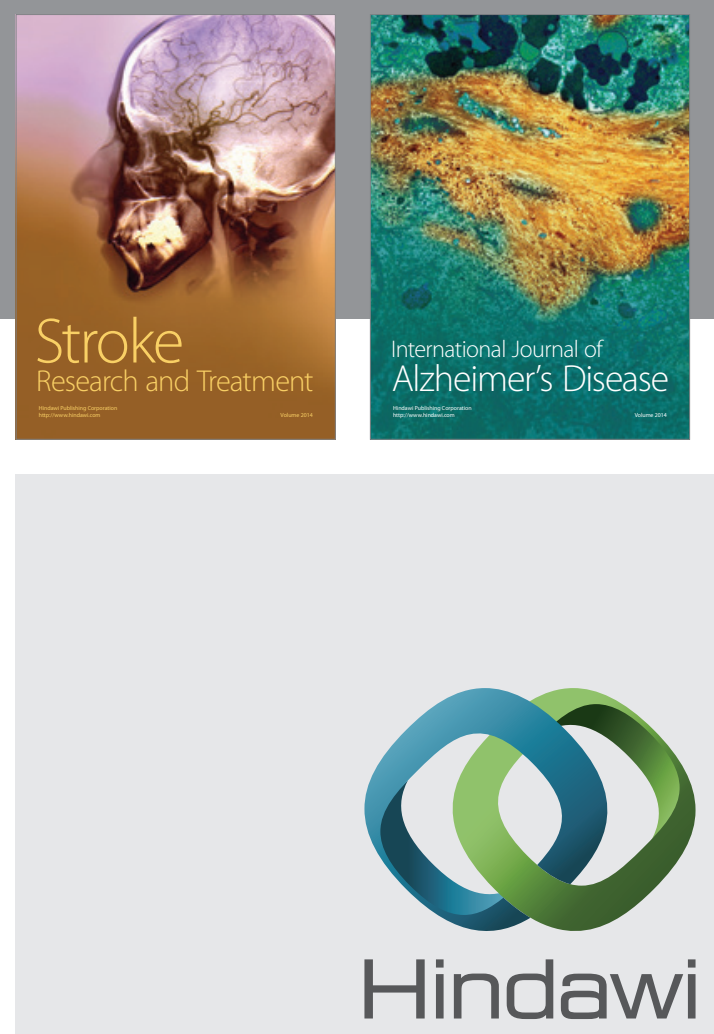

Submit your manuscripts at

http://www.hindawi.com
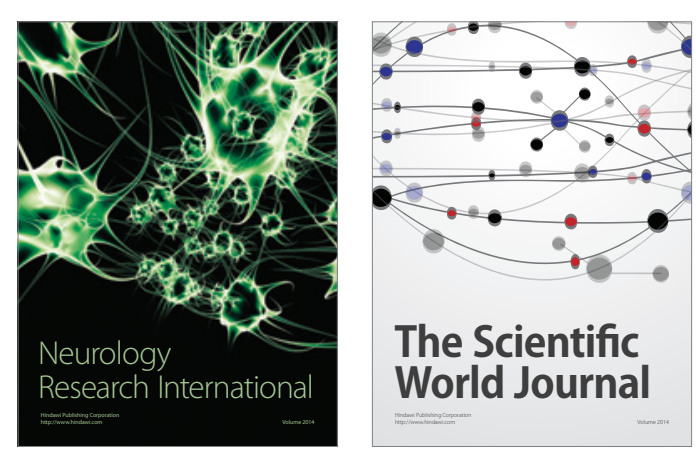

The Scientific World Journal

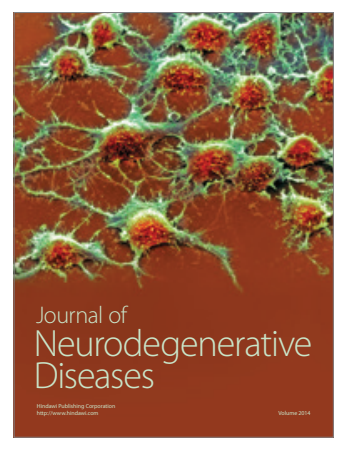

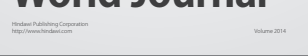

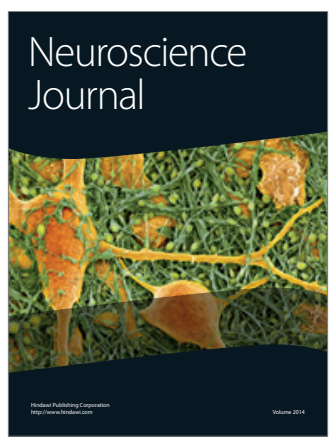

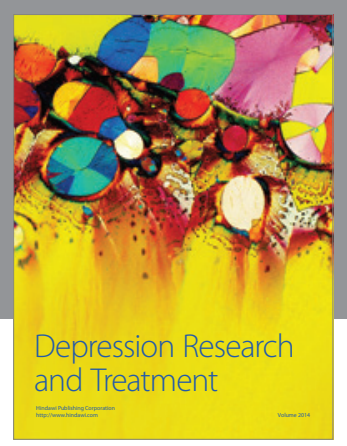
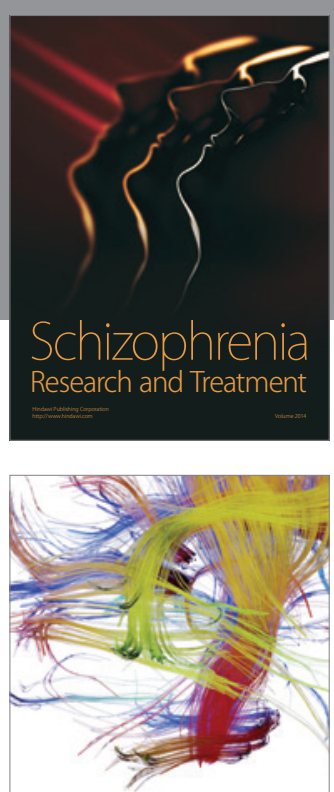

Brain Science

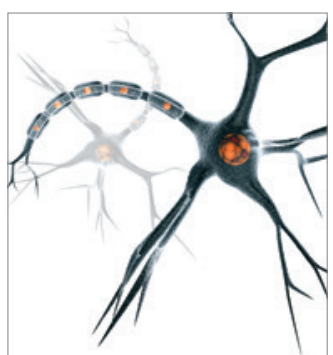

Neural Plasticity
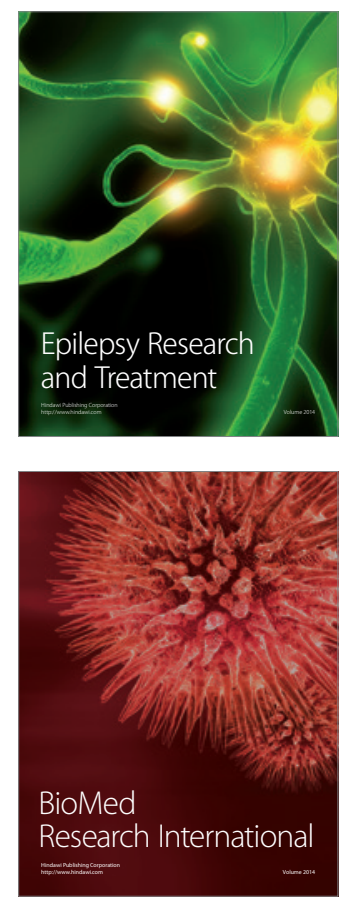

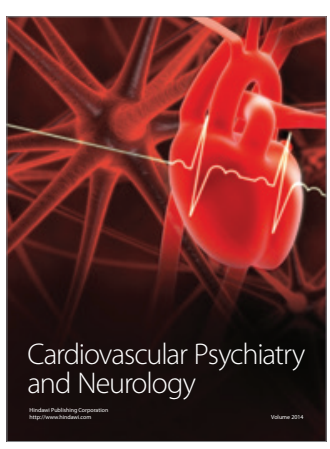

Parkinson's

Disease
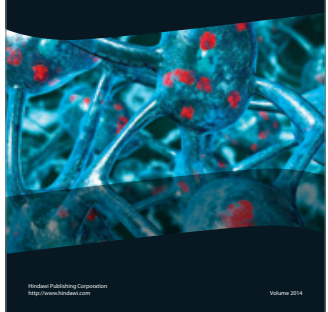